\title{
Major Salivary Gland
}

National Cancer Institute

\section{Source}

National Cancer Institute. Major Salivary Gland. NCI Thesaurus. Code C12999.

One of the three larger salivary glands including the parotid, submandibular and sublingual glands. 